\title{
Analysis of Pap smears in a cytopathology lab of a teaching hospital
}

\author{
Reetu Sharma Baral \\ B and C Medical College Teaching Hospital, Birtamode, Nepal \\ Received: May15, 2020 \\ Accepted: May 31, 2020
}

\section{ABSTRACT}

Aims: This study was done to find out age wise distribution pattern, cellular abnormality and adequacy of Pap smears.

Methods: A retrospective study of 470 Pap smears based on laboratory record was done from September 2019 to April 2020 at B and C Medical College Teaching Hospital, Birtamod, Jhapa, Nepal. Descriptive analysis performed using MS Excel and SPSS 16.

Results: Out of 470 analyzable data $2.55 \%$ had abnormal cytology, all high-grade lesions were in $30-49$ age group and $0.21 \%$ were detected as carcinoma. Mean age of women was 39.2 \pm 10.5 years. Age distribution follows the normal Gaussian curve. Age group of $30-60$ years consists of four-fifth $(75.5 \%, \mathrm{n}=355)$ and Two-third of cases $(66.4 \%, \mathrm{n}=312)$ were of age group 30-49 years.

Conclusions: Pap samples were normally distributed by age. Test requisition forms lack adequate clinical information. Even the inadequately sampled Pap smears were satisfactory for evaluation.

Keywords: cancer, cervix, intraepithelial lesion, Pap smear, screening.

Citation : Baral RS. Analysis of Pap smears in a cytopathology lab of a teaching hospital. Nep J Obstet Gynecol. 2020;15(30):72-75. DOI 10.3126/njog.v15i1.29346

\section{INTRODUCTION}

Pap smear has been an effective tool in the screening of cervical cancer since last many decades. It is safe, reliable and accurate test which helps in detection of pre-cancerous lesions of the cervix. When the lesions are detected before the cancerous stage it is completely treatable. The cost of the test is low so is affordable to the patients as well. The procedure of the test is simple and can be done in out-patient department while vaginal examination is being conducted it does not take extra time and preparation for the doctor as well. Testing is also simple at cytopathological facility with report on the same day.

Cervical carcinoma is the third most common cancer amongst women worldwide while it is first most common cause of female cancer in Nepal for women aged 15 to 44 years. Approximately 2942 new cervical cancer cases are diagnosed annually in Nepal (estimates for 2018). The second common cause of cancer in females aged 15-44 years is breast followed by ovary. ${ }^{1}$

This study was conducted in a tertiary hospital in the eastern part of the country to study the age wise cellular abnormal pattern of Pap smears, adequacy of smears for cytological evaluation and the distribution of sample by age group.

\section{METHODS}

This is a retrospective study done in the Department of Pathology in B and C medical college teaching hospital, Birtamod, Jhapa. The study was conducted from September 2019 to April 2020. The Pap smear samples were collected by Gynecologists within the hospital as well as from health camps organized in different parts of the district. These specimens were received at cytopathology laboratory. The Pap test reports were retrieved from the electronic record maintained at lab and all were classified according to the 2001 Bethesda system for reporting Pap smear cytology. All reports were examined by pathologist.

\section{CORRESPONDENCE}

Dr Reetu Sharma Baral

Department of Pathology

B and C Medical College Teaching Hospital, Birtamode, Nepal

Email: reetu.baral@gmail.com; Phone: +977-9841829242 
Hospital had adopted the conventional Pap screening method. All records were entered into the MS Excel spread sheet and exported to SPPSS window, and then descriptive analysis was performed. Study approval was taken from the hospital and there was no ethical issue to spell out.

\section{RESULTS}

A total of 470 Pap test reports were analyzed. Due to incomplete requisition forms three cases had to be excluded from the study. Age group distribution was done according to the WHO recommendation for screening. ${ }^{2,3}$ The recommended screening age of $30-60$ years consists of four-fifth $(75.5 \%, \mathrm{n}=355)$ of data and $91.7 \%$ (11 out of 12 cases) of abnormal smears. Two-third of cases $(66.4 \%, \mathrm{n}=312)$ were of age group 30-49 years. The samples received from extremes of age $(<20$ and $>70)$ were only $1.7 \%$ $(\mathrm{n}=8)$. Mean age of women was $39.2 \pm 10.5$ years. Age distribution follows the normal Gaussian curve. [Figure-1]

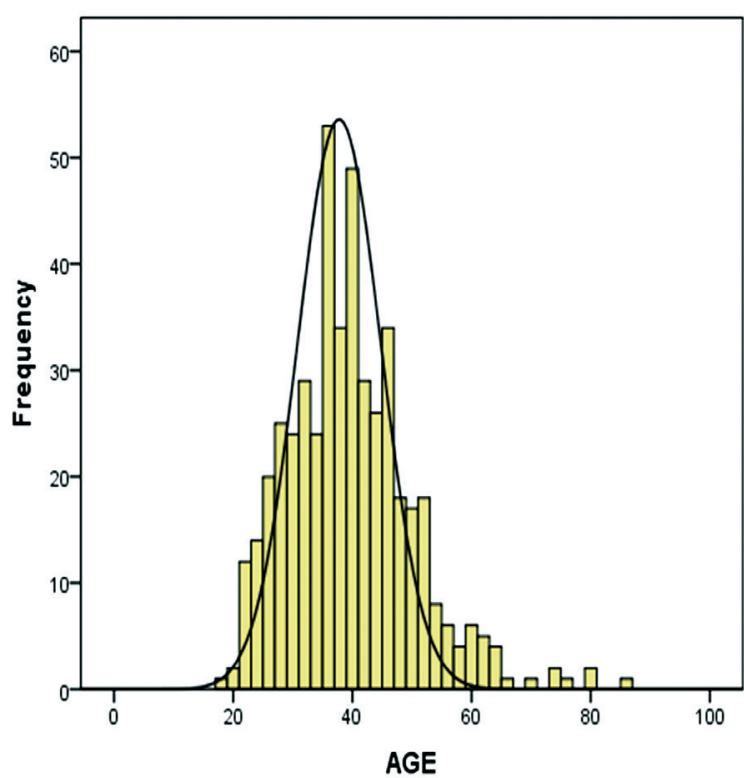

Figure-1: Age distribution of Pap test samples (Age in years, $n=470$ )

The negative for intraepithelial lesion or malignancy was the most common diagnosis $(76.6 \%, n=360)$ followed by inflammatory and atrophic smear; there was only one report of granulomatous smear [Table-1].
Table-1: Cytological diagnosis of non-dysplastic Pap smear report by age group $(n=458)$

\begin{tabular}{|c|c|c|c|c|c|c|c|c|}
\hline $\begin{array}{l}\text { Diagnosis } \\
\text { Agegroutp } \\
\text { (Years) }\end{array}$ & 롤 & 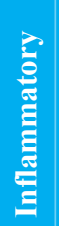 & $\frac{\mathscr{Z}}{\frac{\pi}{2}}$ & 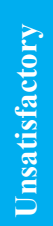 & $\frac{\frac{n}{5}}{\frac{5}{0}}$ & 产 & 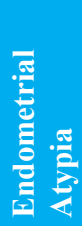 & $\Sigma$ \\
\hline$<20$ & 1 & 0 & 0 & 0 & 0 & 0 & 0 & 1 \\
\hline $20-29$ & 74 & 3 & 0 & 1 & 0 & 1 & 0 & 79 \\
\hline $30-39$ & 137 & 29 & 0 & 1 & 1 & 0 & 0 & 168 \\
\hline $40-49$ & 112 & 25 & 1 & 4 & 2 & 0 & 0 & 144 \\
\hline $50-59$ & 30 & 2 & 9 & 0 & 1 & 0 & 1 & 43 \\
\hline $60-69$ & 4 & 1 & 11 & 0 & 0 & 0 & 0 & 16 \\
\hline $70-79$ & 2 & 0 & 2 & 0 & 1 & 0 & 0 & 5 \\
\hline $80-89$ & 0 & 0 & 2 & 0 & 0 & 0 & 0 & 2 \\
\hline$\Sigma$ & 360 & 60 & 25 & 6 & 5 & 1 & 1 & 458 \\
\hline
\end{tabular}

Abnormal cytology report was obtained in $2.55 \%$ (12 out of 470 ) samples. There was equal number of ASCUS and LSIL ( $0.85 \%$ each from total smears), and only one report of carcinoma at 38 years of age. ASCUS was found in 30-49 years of age [Table-2].

Table-2: Age-wise distribution of abnormal Pap smear tests $(n=12)$

\begin{tabular}{|c|c|c|c|c|c|c|}
\hline Abnormality & $\begin{array}{l}2 \\
\text { Z } \\
2\end{array}$ & 过 & 言 & $\underline{\underline{0}}$ & 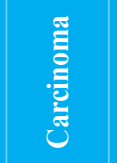 & $\Sigma$ \\
\hline$<20$ & 0 & 0 & 0 & 0 & 0 & 0 \\
\hline $20-29$ & 0 & 0 & 1 & 0 & 0 & 1 \\
\hline $30-39$ & 2 & 1 & 0 & 1 & 1 & 5 \\
\hline $40-49$ & 2 & 0 & 2 & 1 & 0 & 5 \\
\hline $50-59$ & 0 & 0 & 1 & 0 & 0 & 1 \\
\hline $60-69$ & 0 & 0 & 0 & 0 & 0 & 0 \\
\hline $70-79$ & 0 & 0 & 0 & 0 & 0 & 0 \\
\hline $80-89$ & 0 & 0 & 0 & 0 & 0 & 0 \\
\hline$\sum$ & $\begin{array}{c}4 \\
(0.85 \%)\end{array}$ & $\begin{array}{c}1 \\
(0.21 \%)\end{array}$ & $\begin{array}{c}4 \\
(0.85 \%)\end{array}$ & $\begin{array}{c}2 \\
(0.42 \%)\end{array}$ & $\mid \begin{array}{c}1 \\
(0.21 \%)\end{array}$ & 12 \\
\hline
\end{tabular}

A total of 6 specimens $(1.3 \%)$ were limited by inadequate sampling but still found satisfactory for evaluation. In $2(0.4 \%)$ of these cases endocervical component was absent; 4 cases $(0.85 \%)$ showed dense inflammatory cells and hemorrhage obscuring the squamous cells; Clinical information such as menstrual history, parity, treatment, contraception and pelvic examination findings were not available 
in most of the requisition forms. There were only 25 forms $(5.3 \%)$ with pelvic findings filled up. All slides were evaluated with comments on adequacy of sampling.

\section{DISCUSSION}

World health organization (WHO) has recommended cervical cancer screening by Pap smearsuch as 30 years to start for low risk ( 25 for high risk) population till 60 years of age at 3 years interval below 50 years and every 5 years thereafter; and in between 35 and 45 if a woman has to be screened only once in her life time. ${ }^{2,4}$

The Papanicolaou or Pap smear was invented in the 1920s by Dr. Georgios Papanikolaou which was simplified and was introduced in the early 1940s to screen for pre neoplastic conditions of the cervix. Pap smear is the routine test done for screening of cervical cancer all over the world. This test is a simple verifiable test with low cost and can be performed in any Pathology lab without need of expensive equipment; this is why even the poor nations can use this test to screen for cervical cancer.

Deaths from cervical cancer have decreased by more than $70 \%$ over the last 50 years during which the screening test has been widely used. In the USA, mortality rates have declined in the past decades due to prevention and early detection as a result of screening with Pap test ${ }^{5}$. Cervical carcinoma does not develop suddenly from normal epithelium but is presented by a spectrum of intraepithelial changes, which are precancerous lesion.

In this study the abnormal smears including carcinoma were seen mainly among the age group more than 21 and less than 69 years of age. In a study done by Pradhan $^{6}$ in 800 samples, the abnormal smears were seen mainly among age group of 21-40 years and carcinoma was also found mainly in this group.

Pradhan et $\mathrm{al}^{7}$ in 200 samples, all of the women who had atypia, also had inflammation and were between 35 and 50 years of age, a risky age group for the development of CIN and cervical carcinoma. On analyzing 2288 Pap tests in a study done in a hospital in Nepal they had found precancerous and malignant lesions in 65 cases. These cases were analyzed by their age groups, which revealed similar proportion of abnormalities in between 26-35 years and 36-45 years of age group respectively. ${ }^{8}$ ASCUS was seen to be highest in the age group 31-50 years in a study of 1369 samples analysed by Hirachandet $\mathrm{al}^{9}$ in a tertiary centre in Kathmandu. As the age increases the incidence of epithelial abnormality also increases. This is also seen in 880 samples studied by Ranabhat et $\mathrm{al}^{10}$ where $80 \%$ of all epithelial abnormality was seen in patients more than 40 years of age. Proportion of ASCUS (3.2\%) is similar to the report given in Evidence Based Medicine (4\%) ${ }^{11}$ and Vaghela et al $(2.8 \%)^{12}$

The diagnosis of ASCUS is important as it progresses to LSIL, HSIL and SCC. Both two cases of HSIL were seen in the age group of 30 - 49 years, which is seen a decade earlier than in the study done by Sharma $\mathrm{R}$ et $\mathrm{al}^{13}$ in a community hospital in Kathmandu. Cervical cancer is rare in women under 30 years of age and most common in women over 40 years, with the greatest number of deaths usually occurring in women in their 50s and 60s. ${ }^{1}$ In a study done by Dangal $\mathrm{G}^{14}$ in BP Koirala Memorial Cancer Hospital it is seen that the mean age of cervical carcinoma is 46 years that lies in the age group of 30-50 having diagnosis of carcinoma in current study.

According to the Bethesda system, the criteria includes estimations of number of squamous and endocervical cells present, specimen preservation and fixation and the absence of obscuring inflammation and blood. Pap smears have been categorized according to the above mentioned criteria into satisfactory, unsatisfactory or satisfactory but limited by. Patients with unsatisfactory smear whatever maybe the reason usually undergo a repeat pap smear in a few months. But recommendations for the ones with satisfactory but limited by have not been defined well. It has been agreed upon that they should be rescreened in the same way as the ones with satisfactory smears since presence of the readable cells makes it more reliable than completely unsatisfactory ones.

If the adequacy of the smear is limited by absence of endocervical cells, obscuring inflammation or blood, then screening has to be repeated after 12 months. The reason of receiving $0.4 \%(n=6)$ of the slides as inadequate, however, these were evaluated as satisfactory not requiring immediate re-sampling. Early repeat can be done if previous ASCUS was seen, unexplained glandular abnormality, positive 
for high risk HPV, immunocompromised patient, clinician not able to visualize the cervix or sample the endocervical canal, similar obscuring factor in the previous pap test and insufficient previous screening.

In a developing country like Nepal where statistics show a high rate of cervical cancer mortality, suitable methods for detection of cervical cancer has to be implemented. Studies done in Nepal has shown that only $65.7 \%$ patients said they had heard about cervical cancer and only $18 \%$ had heard about or knew about the screening test done for cervical cancer. ${ }^{15}$ Similar results are seen in a study done by Gyawali B et al. ${ }^{16}$ Pap smear coverage was found to be $7.8 \%{ }^{17}$

Pap smear is the single most successful objective cancer screening tool in modern medicine, which is simple, cheap, safe, and practical diagnostic tool for early detection of pre-cancerous lesion in the cervix where cytodiagnostic facility exists. The average reporting time since receipt of slides is one day in majority of samples due to the ease and simple technique of staining the slide. The interpretation done by Bethesda system is simple, not time consuming and easy hence the slides can be read in a short time and reported.

\section{CONCLUSIONS}

The current study sample yields a statistical normal curve. Cervical carcinoma was detected in $0.21 \%$ of Pap specimens from $2.55 \%$ of abnormal cytology. There is gross inadequacy of clinical information in Pap requisition form with only 5.3\% forms adequately filled up and $1.3 \%$ specimens were not adequately sampled but still satisfactory for evaluation. This study recommends clinicians to provide information on pelvic examination findings in test requisition form for Pathologist to have a complete clinical picture as well.

\section{REFERENCES}

1. Bruni L, Barrionuevo-Rosas L, Serrano B, Brotons M, Cosano R, Muñoz J, et al. ICO Information Centre on HPV and Cancer (HPV Information Centre). Human Papillomavirus and Related Diseases in Nepal. Summary Report 7 June 2019. URL:https://hpvcentre.net/statistics/reports/NPL.pdf

2. Family Health Division (FHD).National Guideline for Cervical Cancer Screening and Prevention in Nepal; 2011.

3. World Health Organization. Comprehensive cervical cancer control: a guide to essential practice. Geneva: WHO; 2014.

4. Baral G. Managing cervical cancer in Nepal: need of consensual guideline. Nep J Obstet Gynaecol. 2009;4(1):3-10

5. American Cancer Society. Cancer facts and figures 2018. URL: https://www.cancer.org/research/cancer-facts-statistics/ all-cancer-facts-figures/cancer-facts-figures-2018.html

6. Pradhan P. Prevention of carcinoma of cervix: role of Pap smear screening. Nepal Med Coll J. 2003;5(2):82-6.

7. Pradhan N, Giri K, Rana A. Cervical cytological study in unhealthy and healthy looking cervix. Nep J Obstet Gynaecol. 2007;2(2):42-7.

8. Ghosh A, Rao S, Pramanik T. Is it relevant to screen women younger than 26 years for pre-cancerous and malignant cervical lesions? Asia Pacif J Clin Path. 2005;6.

9. Hirachand S, Bajracharya J, Pradhanang S, Lama S. Detection of abnormal cervical cytology in Papanicolaou smears in a tertiary care center. J Nepal Med Assoc. 2013;52(191):462-5.

10. Ranabhat SK, Shrestha R, Tiwari M. Analysis of abnormal epithelial lesions in cervical Pap smears in Mid-western Ne- pal. J Path Nep. 2011;1:30-3.

11. Lappe J, Gossett DR. Evidence-based cervical cancer screening: the modern evolution of the Pap smear. In: Nikolaos MS, editor. Evidence Based Medicine - Closer to Patients or Scientists. 2012. ISBN 978-953-51-0504-6. URL: http://www. intechopen.com

12. Vaghela BK, Vaghela VK, Santwani PM. Analysis of abnormal cervical cytology in Papanicolaou smears at tertiary care center: a retrospective study. International Journal of Biomedical and Advance Research. ISSN: 2229-3809 (Online).

13. Sharma R, Baral G, Dangal G. Analysis of Pap Smear Database in a Community Hospital. Nep J Obstet Gynaecol. 2015;9(1):21-5. ISSN 1999-8546. URL: http://njog.org.np/ njog/index.php/njog/article/view/75

14. Dangal G. Initial experience of radical hysterectomy for early cervical cancer at a cancer hospital in Nepal. J Nepal Med Assoc. 2004;43(156):297-302.

15. Shrestha J, Saha R, Tripathi N. Knowledge, Attitudeand Practice regarding Cervical Cancer Screening Amongst Women visiting Tertiary Centre in Kathmandu, Nepal. Nep J Med Sci. 2013;2(2):85-90

16. Gyawali B, Keeling J, van Teijlingen E, Dhakal L, Aro AR. Cervical cancer screening in Nepal: ethical considerations. Medicolegal and Bioethics. 2015;5:1-6. DOI: https://doi. org/10.2147/MB.S77507

17. Ranabhat S, Dhungana G, Neupane M, Shrestha R, Tiwari M. Smear coverage and effect of knowledge and attitude regarding cervical cancer on utilization of the test by women in Udayapur district of NepaL. J Chitwan Med Col. 2014;4(10):31-5. 